\title{
Editorial
}

\section{THOSE GAPS}

It has become trite to state that serious gaps in our knowledge of leprosy still exist. There are, however, other gaps, gaps that may account for the sobering fact that this disease has, in the world as a whole and up till now, successfully resisted the combined efforts of governments, voluntary bodies and international agencies.

The factual appraisals of the results of leprosy control schemes in different countries which have appeared in the previous issue of Leprosy Review and in the present one provide not only encouraging grounds for hope, but also substantial reasons for concern. The crux of the matter has been succinctly expressed by Dr. P. K. Duraiswami, the Chairman of the Hind Kusht Nivaran Sangh, in his report for the year 1968, which has just come to hand: "With far better tools than we have ever had, we have now greater chances than ever to banish leprosy not only from India, but from the whole world. But why then is leprosy still a major health problem with us? The answer lies mainly in the fact that enlightenment of the public and even of the medical profession has lagged far behind medical progress"'.

The gap between what is known and what is practised, between the research laboratory and the field of action, the gap between the best leprosy control schemes and the worst, between good integrated planning and its almost entire absence-those gaps are patent, and real, and serious. It would be both idle and misleading to attribute these glaring differences entirely or mainly to disparity of the resources available for leprosy control, though at first sight the provision of health care would seem to be less daunting a prospect when $\$ 50$ U.S. is available per leprosy-patient/day than when $\$ 1$ U.S. is all that can be spared per head per year for all medical services, including leprosy. Fortunately, leprosy still makes an appeal to charitablyminded people, otherwise the outlook for leprosy control would be bleak indeed.
But there is more to it than that. In a recent paper, Labusquière (1969) refers to the sober optimism now prevailing in some ex-French African territories (with the notable exceptions of Gabon and the Cameroons) regarding leprosy. Mass treatment schemes, mobile teams, resolute case-finding surveys, single standard therapy regimes-these seem to provide the reason for the satisfaction noted. The total numbers of patients under treatment, after progressive annual increases, are showing definite reduction; new cases number less than discharges; the back of the endemic has been broken. But it would unfortunately be unjustifiable to extrapolate these excellent results from a total population at risk of 10 millions or so, to a world where leprosy is a more serious disease, more stigmatizing and more dreaded, a world in which the methods that have achieved such results in West Africa, are, for some valid reason or other, not yet applied, or perhaps not even applicable. There may be a higher prevalence of leprosy in tropical Africa, but the lepromatous/tuberculoid ratio is far lower. As Browne (1968) stated at the Ninth International Leprosy Congress, "In any given context there must be one plan, locally applicable and locally feasible, that is better than all the others". Other countries may with profit adapt from West Africa; they do not have to adopt an identical plan of campaign. However, in those countries where leprosy is feared, and hidden till it is no longer possible to hide it, where the population is reckoned in hundreds per square mile rather than in tens or even in units, where health services are extremely thin on the ground or even (in rural areas) virtually non-existent, the gap between the ideal and the possible is immeasurable, and at present apparently unbridgeable. It is, for instance, reliably reported from one country that of an estimated total of 80,000 sufferers from leprosy, only 6000 are at the moment receiving treatment: the rest are hiding their infection and their fears until their deformities 
drive them to swell the ranks of the beggars. In another country, where repressive legislation still prevents the open diagnosis and open treatment of leprosy, only one leprosy sufferer in 50 has successfully braved official opprobrium and possible incarceration to obtain treatment for his disease.

There are local gaps within countries, vast lacunae of unmet need. The articles appearing in this Review have shown what can be done within the framework of the circumstances, the environment, the social background, and the economic possibilities of such countries, but overall coverage is the exception rather than the rule. The success of good planning and good organization is frequently attributable to the personal qualities of the leaders-their knowledge, vision, and enthusiasm. In Brand's words, it is a "matter of caring"-at all levels-and without such attention to such an essential factor, the best plans and the best organization will of ten go awry.

There is a certain widespread feeling of disillusionment at the slow progress registered in many leprosy control schemes. It is not only the World Health Organization and UNICEF (1965) that have expressed concern at the high continuing cost of many such projects when examined in relation to effective leprosy control, that is, the number of patients rendered noncontagious and a falling number of new infections. Disproportionate sums are still being sunk in constructing costly villages for exleprosy patients, where they will evince no desire for social reintegration or rehabilitation. It is surely unjustifiable to devote, in the context of poverty and subsistence farming, sums of $\$ 750$ U.S. per head for such a project. In the light of leprosy control, this is unrealistic.

The best methods of leprosy control applicable to the local situation are much better, and of ten less costly than others: they should be applied. Treatment regimes, in some schemes, could with advantage be simplified in the interests of medical effectiveness, spread of effort, and economy. Self-treatment may be the answer in some areas, or less frequent supervisory visits by scarce qualified staff.

Another gap emphasized in these and other reports is that which exists between the progress announced from laboratory and field, and its application to the immediate and pressing problems of leprosy control. If, after some months of treatment, patients with lepromatous leprosy are no longer contagious, it is unnecessary to subject them to costly in-patient segregation and at the same time deprive other patients of the treatment they need because of the resulting lack of funds.

The gap between the research scientist and the field worker is perhaps best exemplified by the increasing sophistication of leprosy research and the increasing specialization and fragmentation of knowledge in this branch of science. This kind of research is very necessary, and very exemplary, provided that we bear in mind Health Minister Robinson's salutary admonition (1968), that we should not allow our "interest in the cellular reaction in the mouse to cloud" our "concern for the human plight of the man". The latter is, of course, the ultimate motivation of much leprosy research, and "pure" research, so-called, not infrequently becomes "applied" research, to the benefit of leprosy patients. The new work in immunology and biochemistry, and the prospects of increasing use of the thymectomized-irradiated mouse in developing a protective vaccine, are examples that come readily to mind. The identification of the point of action of new drugs opens up exciting and intensely practical prospects for the treatment of leprosy and for its control.

It would be unrealistic to expect more money for leprosy, or for leprosy to be accorded a higher priority in terms of government budgetary allocations or staff than it now receives, but it would be wrong not to expect a greater appreciation of the economic cost to the community of this disease and a greater realization of the potential of leprosy study in relation to scientific and clinical investigations of many kinds. And in view of the overriding 
importance of the non-medical and nonscientific factors in leprosy control, it would be especially wrong at this time to relinquish efforts to educate doctors and laity alike in the modern knowledge about leprosy.

In many countries those engaged in leprosy campaigns are not reading enough. Preoccupations, sheer "busyness", language difficulties, lack of professional contacts and stimulus, the laboratory orientation of much published work -all are adduced as reasons for not reading about what other leprosy workers are writing and thinking. But this gap is not unbridgeable. The busiest people somehow find time to record, to review, to analyse, and to write. They also find time to read. Verb. sap. Elsewhere, we welcome the appearance of the first number of the East Africa Medical Bulletin, whose main purpose is the dissemination of new knowledge to the "man in the field", medically qualified or not. This example might well be followed in other local contexts.

With the continued collaboration with govern- ments of voluntary bodies and international agencies, and a fuller exchange of information at all levels, the aforementioned gaps could and should be bridged. "If only we could together apply existing knowledge, it is not beyond the realms of possibility that leprosy could be controlled in our generation, and eradicated in the next" (Browne, 1968). This task will need more than words and slogans and resolutions at Congresses. Bridge-building is hard work and, in leprosy, urgent work.

\section{REFERENCES}

BRowne, s. G. (1968). Priorities and co-operation. Blueprints and guidelines. International .Journal of Leprosy, 36, 544.

DURAISwami, P. K. (1968). Hind Kusht Nivaran Sangh Report, p. 1 .

LABUSQUiÈre, R. (1969). La lutte contre la lèpre en Afrique centrale. Acta Leprologica, 36, 5.

Robinson, K. (1968). Opening Address, Ninth International Leprosy Congress, London. International .Journal of Leprosy, 36, 542 .

WORT.D HEALTH ORGANIZATION (1965). Review of leprosy control projects. E/ICEF /5()9, section 10 . 